\title{
MOOCS AS A KEY STRATEGY FOR UNIVERSITY ORIENTATION
}

\author{
Ilaria Merciai, \& Ruth Kerr \\ Federica Weblearning Centre, University of Naples Federico II (Italy)
}

\begin{abstract}
In a global knowledge society, there is a growing need for a highly-qualified, and differently-qualified, workforce. Leading to heightened interest on the part of European and National Institutions in student demographics, and figures like total number of undergraduates, graduates, and STEM students. In Italy, the total number of people in the 25-34 age range who have a degree is $20 \%$ compared to the OECD average of $30 \%$. And compared to graduate numbers in the rest of Europe, Italy is almost at the bottom of the league table. Italians score similarly on levels of digitalization. Student dropout figures in Italy also compare unfavorably with the rest of Europe. Against this background, European directives state the need for strategic intervention on the part of universities, in orientation and education. On a national level, the Ministry for University Education and Research (MIUR) is focusing on ways of responding to these challenges. And MOOCs and multimedia learning have been cited as a potential tool to help address them. This paper looks at how MOOCs, since January 2019, are being used as part of the new strategy for university orientation for school-leavers at Federica Weblearning, the Centre for Innovation and Research into online learning at the University of Naples Federico II. It explores how courses are structured to address the needs of this particular audience, how students are reached, student engagement encouraged and how success of the initiative is measured.
\end{abstract}

Keywords: $M O O C$, multimedia learning, orientation.

\section{Introduction}

Federica Weblearning is a University Centre for Experimentation and Innovation in open and multimedia learning at the University of Naples Federico II. Starting out with Open Courseware in 2007, Federica moved into the MOOC sector in 2015 and now has a portfolio of 150 MOOCs hosted on its own Federica.eu platform and on edX, the international provider headed by Harvard and MIT. The main driver behind MOOCs development was to enhance the University core business of preparing students for degrees by offering a more flexible, digital alternative/supplement to in-house teaching, which was more in line with 21st century student expectations. However, Federica also realized that its MOOC audience was much broader than this and so, in 2017, Federica reviewed its MOOC strategy in readiness for a new-look home-page that better addressed the changing audience. The results, presented in a previous paper (Kerr, R., Reda, V., 2017), defined the four pillars of the Federica Institutional MOOC strategy: Core Business; Lifelong Learning, Internationalization and, last but not least, Orientation, addressing the large numbers of high-school leavers who are facing important life and career decisions.

Although a university degree is still seen as the baseline qualification for most middle level jobs (Selingo, J., 2017), and, in an information society the need for a more highly-skilled workforce increases, a 2016 EU survey shows that while 30 million students successfully graduated from University, another 3 million dropped out. The reasons for abandoning university studies are wide-ranging but often relate to the degree program not responding to real needs $(22 \%)$, and unexpected difficulty of the course work $(18 \%)$. 
Figure 1. EUROSTAT 2018.

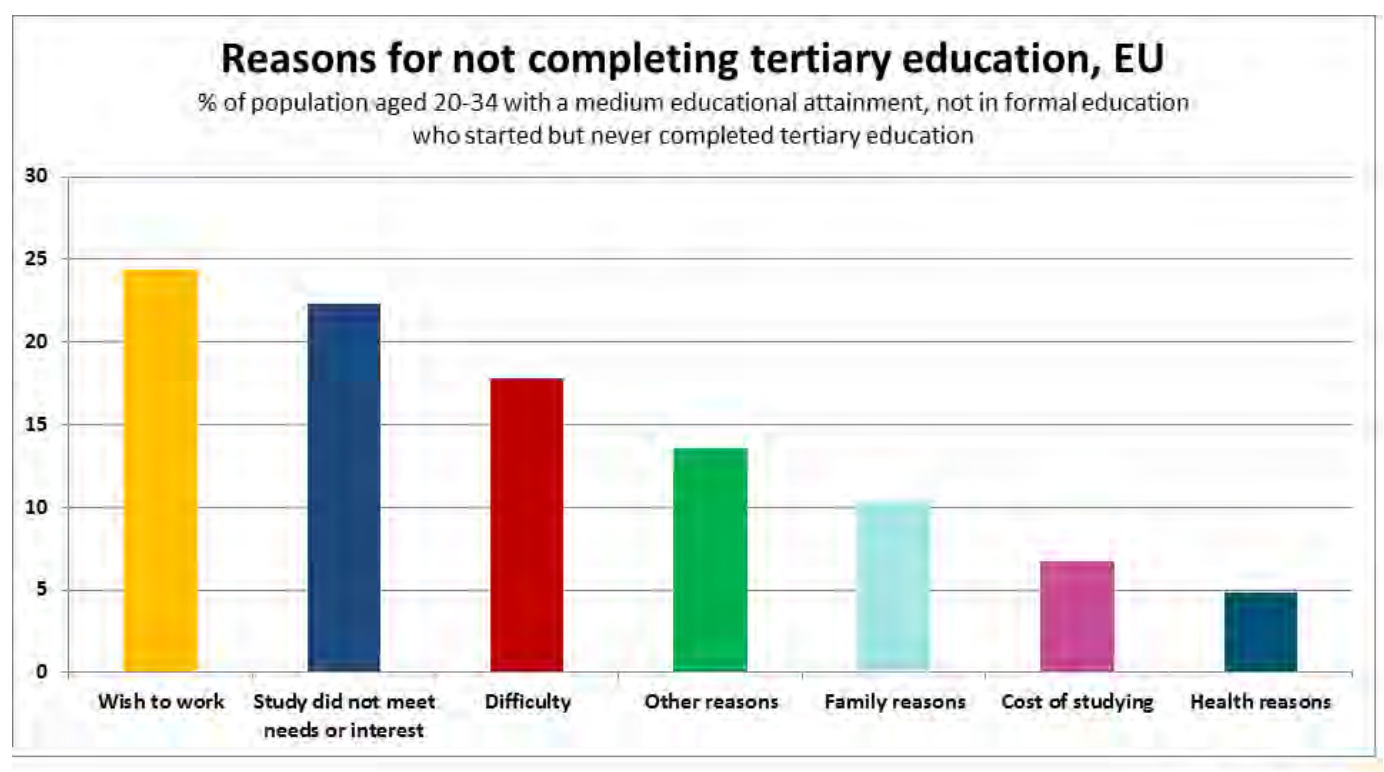

eurostat E:

The European Commission issued directives stating the need for strategic intervention on the part of universities, in orientation and education. However, the uptake has not been very widespread.

\section{Online orientation initiatives}

On a global level, over the last five years there have been various initiatives in the e-learning sector that aim to bridge the gap between school and higher education for secondary school students wishing to enter university. One notable example is Khan Academy a not-for-profit organization which offers learning tools primarily for school-age students, and teachers. It also provides services, such as mentoring for parents and teachers and other tools dedicated to helping students navigate college admissions, career choices, personal finance and entrepreneurship. On the other hand, leaders in the e-learning sector on higher education have designed programs that are specifically focused on student orientation. In particular, in the US, edX, the Harvard-MIT MOOC provider, is offering a project called "Get College Ready. Get Ahead. Get Learning” (https://www.edx.org/high-school), which consists of 50 courses with high relevance to high schoolers, including AP exam preparation, and introductory college freshman-year courses. At the same time, Futurelearn, leader of online education at a European level, since 2015 launched a project called Futurelearn Choices (https://www.futurelearn.com/courses/collections/going-to-university). It offers a collection of courses, specifically designed for students aged 16-19, with the purpose of giving an overview and a sample of different universities and university subjects that they may be interested in, in order to choose the right degree, university or career (Class Central, 2015).

France also seems to play a leading role in the field, with initiatives from the national institutional MOOC platform FUN (https://www.fun-mooc.fr/) and RenaSUP (Réseau national d'enseignement supérieur privé, https://www.renasup.org/).

FUN offers a BAC preparation course, MOOCs on key subjects not taught at school (medicine, law, psychology) and on STAPS (sciences et techniques des activités physiques et sportives), as well as a MOOC on how to successfully apply to top universities.

Renasup offers its Partner Catholic lycées an Orientation MOOC to help teachers and students understand Ministerial Reform (http://www.mooc-renasup.org/index.php)

The University of Torino in Italy offers 20 open access courses via its Start@UniTO project, in conjunction with the San Paolo Company. These are aimed at final year High school students with a view to better aiding student choice of course. 


\section{Scenario in Italy}

A 2017 OECD report on Education Policy Outlook in Italy states that in Italy, the share of 25-34 year-olds with at least upper secondary education was $74.4 \%$ in 2015 (compared to the OECD average of $84.1 \%$ ). Tertiary education attainment of 25-34 year-olds is the lowest among OECD countries; in 2015, $25.1 \%$ had attained tertiary education (compared to the OECD average of $41.8 \%$ ). Dropout rates compare equally unfavorably Government reforms in response to this include the three-year National Plan for Digital Education (Piano Nazionale Scuola Digitale, PNSD), which aims to improve digital competencies of both teachers and students, through a complex set of actions ranging from upgrading Internet connections in schools to setting up learning environments in which creativity and laboratory activities are possible. In co-operation with the European Strategy for Education and Training (ET2020), MIUR is implementing the National Operational Programme 2014-20. One objective of the programme is to reduce regional performance differences by decreasing the early school-leaving rate of 18-24 year-olds to below $16 \%$ by 2020 (from $17 \%$ in 2013). Italy achieved this target nationally in 2015, but many regions are still far from it, including Campania. MOOCs are seen as one of the possible strategies for achieving this target. Funding is provided by the European Regional Development Fund (27\%) and the European Social Fund (73\%). The Federica orientation initiative through MOOCs is seen as a possible contribution to improving these critical performances, as well as to providing digital learning contexts within the high school curriculum.

\section{4. "Federica Orienta" initiative and its methodology}

In January 2019 Federica Weblearning decided to launch an intensive MOOC based orientation initiative in conjunction with the Regional Education Council called "Federica Orienta" that is designed to enable students to have a better understanding of what study at university, and of specific disciplines, entails, and thus to help them make more reasoned degree choices in line with personal competences and aspirations.

The project is designed with two main components, online and offline (face-to-face). The online phase comprises specifically designed short MOOCs, called metaMOOCs, which are hosted on the main website of Federica.eu and are available to everyone. Additionally, the program is structured with face-to-face presentations and workshops at schools for teachers and students in the classroom, as explained in the subsequent paragraphs.

\subsection{Online phase}

The metaMOOCs are offered in the 4 scientific-disciplinary areas available at the university: health, sciences, social and humanities studies.

Figure 2. Federica.eu - Orientation Section.

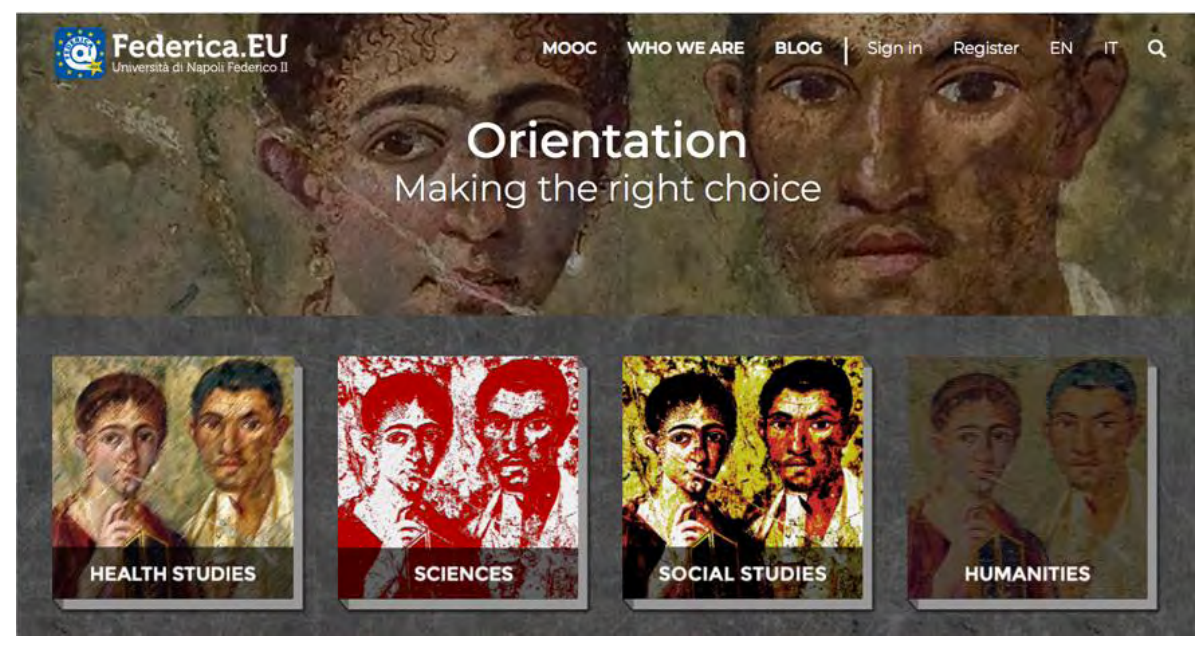


The aim of the online content is to replicate the on-campus experience, introducing students to the subject matter, the teachers, the methodology and giving an idea of the level of difficulty. The emphasis is on subjects that tend to attract large numbers of applicants but which are not included in the High School curriculum, like engineering, law and medicine.

The metaMOOCs offer 4 alternative or complementary pathways. The first is a brief and lively overview of different disciplines via engaging video trailers. The second category invites students to follow one complete lesson of a subject of their choice, thus getting a feel for the teaching style, level of difficulty of input, as well as assessment format and content. The third MOOC category offers longer chunks of learning for students who want to prepare specific modules before actually enrolling at University and maybe get ahead. The fourth is an invitation to teachers, as multipliers, to engage students in orientation via a class project that involves the creation of a digital artefact to be shared on the Federica platform.

1. Trailer - the engaging trailers give an overview of subject content and what a course in this subject would involve

2. First Lessons - compilations of highlights from the first lessons of MOOCs in specific subjects

3. Learn more - in-depth exploration of a specific subject via a complete short MOOC.

4. Tool kit -Classes / Students are invited to create a multimedia report of their own orientation learning journey, which can be published and shared on the Federica platform

Classes are invited to participate in creating their own metaMOOC as a result of their exploration and learning experience on the Federica.eu platform. Or as a result of any other successful orientation activity they have been engaged in. Fundamentally, the MOOCs present with a high level of granularity so students can harvest chunks of learning from diverse MOOCs and connect them around a narrative of their own learning and orientation experience on Federica.eu, to form a recommended learning journey and/or reflection of their own making in the form of a video, mini-MOOC or BOOK, which they can then publish on the Federica.eu website and offer to other students.

\subsection{Offline phase}

To accompany and explain the potential of metaMOOCs for orientation, a series of workshops are being run by the Federica team with involved schools in the local Region. These workshops involve liaising with the Head Teacher, and are organized in conjunction with the Head of Orientation for classes of final year students. During the workshop the Federica team present the four different pathways while the students experiment navigation around the metaMOOCs on their mobile devices. The students are also presented with project guidelines that reinforce how to use the metaMOOCs and also propose various formats that can be used for the final compilation of their own metaMOOC, including video-story, mini MOOC or book.

Federica representatives maintain email contact with class teachers and offer support and ideas throughout their class's orientation journey, and they return to the school to verify students' progress on their multimedia products before they are finally published.

\section{Results}

As the project is still in its early stages, it is difficult to measure the concrete results and impact for teachers and students, but our overview since February 2019, seems to be positive.

In terms of the online phase, we registered more than 13,800 page views, and 600 students enrolled in the metaMOOCs.

15 secondary schools in the Campania Region who are heading for university entry in 2019 have been engaged in the offline phase, via workshops, presentations and meeting with final year students and their teachers. Many other appointments are in the pipeline for an early start with the 2020 intake for the offline phase.

Three video stories created by students are in production, narrating a positive learning/orientation experience in the context of literature and biology.

It is difficult to measure the success of the project, but participants are asked to complete a survey for the collection of qualitative data that can at least enable us to create positive feedback loops, adjusting the approach in accordance with student needs. Workshops are organized for the Autumn term with the teachers involved in the projects, to discuss the feedback emerging from the surveys and to define the road map for the subsequent year.

For now the majority of registered users are focusing on content in the field of humanities, engineering and agriculture, which will enable us in the future to map emerging trends/preferences on the part of the Italian Liceo audience. 


\section{Conclusions and discussion}

As school-leavers have to make difficult decisions about whether to study at university or not, and which subject would best prepare them for personal fulfilment as well as the job market, it seems likely that they will be negatively influenced, at least in Italy, by rising costs of tertiary education, high unemployment rates even amongst graduates, and high university dropout rates. Online orientation initiatives, like the Federica meta-moocs, seek to provide a valid introduction to the on-campus experience, to better inform potential students of subject content, teaching methodology and levels of difficulty. They also introduce students to an online campus, a valid alternative study context for $21 \mathrm{st}$ century students.

The metaMOOCs portfolio will be extended to include preparation courses for university entrance exams in faculties where competition for places is so high. Future developments will also increase levels of student interaction to foster the digital competencies and soft skills that are in demand in the $21^{\text {st }}$ century workplace.

The Federica platform also offers four online Bachelors courses in Computer and Mechanical Engineering, Tourism Management and Business Administration, and this orientation initiative via metaMOOCs prepares students well for an eventual decision to prepare their degree online while working too.

Another future aim of the project is to increase teacher involvement through training workshops in MOOC production and delivery.

\section{Acknowledgements}

A special thanks to our colleague Sofia Thomaidou for her support in understanding the existing scenario in the field.

\section{References}

Class Central. (2015). Five Reasons High School Students Should Consider MOOCs. Retrieved from: https://www.classcentral.com/report/five-reasons-high-schoolers-consider-taking-moocs/

Eurostat. (2018). Work beats study for $25 \%$ of university drop-outs. Retrieved from: https://ec.europa.eu/eurostat/web/products-eurostat-news/-/DDN-20180404-1

Istat. (2017). Livelli di istruzione della popolazione e ritorni occupazionali: i principali indicatori, 2017. Retrieved from: https://www.istat.it/it/files/2018/07/Indicatori-dellistruzione.pdf

Kerr, R., Reda, V. (2018). How MOOCs can make a difference, in EC-TEL Practitioner Proceedings 2018: 13th European Conference On Technology Enhanced Learning, Leeds, UK, September 3-6, 2018

OECD. (2017). Education Policy Outlook: Italy. Retrieved from: www.oecd.org/education/policyoutlook.htm

OECD. (2017). Strategia per le Competenze dell'OCSE, Sintesi del rapporto: Italia. Retrieved from: https://www.oecd.org/skills/nationalskillsstrategies/Strategia-per-le-Competenze-dell-OCSE-Italia2017-Sintesi-del-Rapporto.pdf

Selingo, Jeffrey, J. (2017). The future of the Degree. Chronicle of Higher Education Special report How Colleges Can Survive the New Credential Economy. 